\title{
TX PROCESS SIMULATE AS A MEANS TO INCREASE PRODUCTION IN THE ENTERPRISE FOR THE PRODUCTION U-PROFILES
}

\author{
Jozef TROJAN, Peter TREBUŇA, Marek KLIMENT \\ Technical University of Kosice, Faculty of Mechanical Engineering, Kosice, Slovakia, EU \\ jozef.trojan@tuke.sk, peter.trebuna@tuke.sk,marek.kliment@tuke.sk
}

https://doi.org/10.37904/metal.2019.997

\begin{abstract}
The subject of this work is a production line in an anonymous enterprise. It is a production process of forming U-profiles of different thickness and structure. Our task was to thoroughly analyze the current situation of bending and cutting processes in the workplace, find manufacturing errors and design the assembly line with the Tecnomatix Process Simulate. Therefore, it was necessary to model the current state first so that it was possible to first detect any shortcomings and downtimes and only then optimize it. Subsequently, the proposed solutions were verified by means of modeled simulation of the selected workplace and by time analysis, time savings or other modifications leading to production optimization were found.
\end{abstract}

Keywords: Process Simulate, simulation, effectiveness, innovation

\section{INTRODUCTION}

Nowadays, every company and especially engineering companies need change during their life cycle. A few years ago, businesses used testing and testing of various alternatives to improve material flow and manufacturing processes. These methods were very costly, time consuming and, of course, reduced production capacity. Nowadays it is impossible.

The transition to digital production has become increasingly popular with the growth of the quantity and quality of computer systems in manufacturing plants. A digital business can be defined as a type of strategy that governs an enterprise when it uses digital 3D models of real production, where it can make innovations, changes, and several options can be tried before any of the alternatives is introduced into a real running system. Tecnomatix represents a comprehensive portfolio of digital manufacturing solutions (the so-called digital factory). The digital factory helps to innovate thanks to the possible interconnection of all production disciplines from design and planning, through simulation and verification to production itself. Built on Teamcenter Manufacturing PLM, Tecnomatix provides the most versatile set of manufacturing solutions on the market today. Tecnomatix consists of several modules.

In this work, Process Simulate is used as a digital tool that allows you to virtually verify assembly plans from concept to production start to help reduce risks. The ability to take advantage of 3D product and resource data facilitates virtual verification, innovation and commissioning of complex manufacturing processes, resulting in faster starts and higher production quality. Process Simulate enables the verification of outputs from individual production process segments such as: assembly processes, welding, workforce, continuous processes such as laser welding and bonding, and a sufficient number of robotic processes simulated in the same environment, allowing the virtual production area to be simulated. Simulation faithfully mimics real human behavior, robotic domain controllers, and PLC logic.

\section{MODELING IN 3D ENVIRONMENT}

We have created virtual 3D models with SolidWorks software for individual machines and equipment located in the factory production hall. To begin drawing the model itself, we need to choose the plane in which we will model. On the plane of modeling, it doesn't matter, everyone chooses the plane in which he is taught to draw 